\title{
Microbe-mediated synthesis of antimicrobial semiconductor nanoparticles by marine bacteria
}

\author{
S. Rajeshkumar $\cdot$ M. Ponnanikajamideen • \\ C. Malarkodi · M. Malini • G. Annadurai
}

Received: 7 January 2014/Accepted: 6 March 2014/Published online: 25 March 2014

(c) The Author(s) 2014. This article is published with open access at Springerlink.com

\begin{abstract}
Development of bio-mediated synthesis of CdS nanoparticles is one of the important fields in nanoparticles. The present investigation demonstrates the eco-friendly synthesis of cadmium sulfide nanoparticles using Enterococcus sp. (RMAA). The formation of an intense peak at $410 \mathrm{~nm}$ in the UV-Vis spectrum reveals the synthesis of $\mathrm{CdS}$ nanoparticles. The crystalline natures of the synthesized CdS nanoparticles were identified by X-ray diffraction assay. The scanning electron microscope analysis shows the formation of spherical-shaped CdS nanoparticles with a size range of about $50-180 \mathrm{~nm}$. Fourier transform infrared spectrum shows that the synthesized CdS nanoparticles are capped with bimolecular compounds which are responsible for the reduction of cadmium sulfate to sulfide nanoparticles. The resulting $\mathrm{CdS}$ nanoparticles were tested for antibacterial activity using agar well diffusion method against the test cultures of Serratia nematodiphila, Escherichia coli, Klebsiella planticola, Vibrio sp. and Planomicrobium sp. having good zone of inhibition. The fungicidal activity of $\mathrm{CdS}$ nanoparticles against pathogenic fungus Aspergillus niger and Aspergillus flavus produced a good zone of inhibition. The novel green chemistry approach is an eco-friendly and reliable process and suitable for large-scale production.
\end{abstract}

Keywords Enterococcus sp. CdS nanoparticles . Semiconductor - Extracellular synthesis - Antibacterial activity

S. Rajeshkumar $(\bowtie) \cdot$ M. Ponnanikajamideen · C. Malarkodi · M. Malini · G. Annadurai

Environmental Nanotechnology Division, Sri Paramakalyani Centre for Environmental Sciences, Manonmaniam Sundaranar University, Alwarkurichi 627412, Tamilnadu, India

e-mail: j3ssrajesh@gmail.com

\section{Background}

Nanotechnology is a new, rapidly growing field with application in science for the purpose of producing new materials at the nanoscale level. The word 'nano' represents billions of meters $\left(10^{-9}\right)$. In recent years nanoparticles are important and have created an impact in the areas of chemical energy, electronic and biological sciences. These particles are synthesized by physical, chemical and biological methods [1]. Many nanoparticles, such as silver [2], gold [3], $\mathrm{ZnS}$ [4] and $\mathrm{TiO}_{2}$ [5], have been synthesized using bacteria. Applications of nanoparticles in the biomedical field has been developing very vigorously nowadays, e.g., antibacterial applications [6, 7]. Antifungal activities of $\mathrm{CdS}$ have been reported by various researchers [8]. The microbial synthesis of nanoparticles had been recently recognized as a promising source of nanomaterials [9]. CdS has promising applications in technical fields such as photochemical catalysis, gas sensor, detectors for laser and infrared, solar cells, nonlinear optical materials and various luminescence devices [10-13]. CdS nanoparticle synthesis has been a modern growing field of research due to its important optical, physical and chemical properties. In recent years, many techniques have been introduced for the synthesis of CdS nanoparticles. CdS it's a group of chalcogenides and having application in photoconductive glasses for television and Xerox machines [14]. CdS is a II and IV group of semiconductor and the bulk amount of CdS has a hexagonal shape. CdS nanoparticles are important semiconductors with a direct band gap of $2.4 \mathrm{eV}$ at room temperature, and these nanoparticles are attached to the photocatalysis light-emitting diode and solar cells due to their nonlinear properties. The melting point of $\mathrm{CdS}$ nanoparticles is $1,600{ }^{\circ} \mathrm{C}$. CdS has a high amount of visible light-detecting properties among the other semiconductors. 
Cadmium sulfide is a widely used semiconductor that has many applications such as in optoelectronic and solar cells, photodiodes, light-emitting diodes, nonlinear optics and heterogeneous photocatalysis. In the last few decades, a number of techniques have been reported for the synthesis of CdS nanoparticles [15-17]. Nowadays, CdS nanoparticles are widely used in photonic applications. Many studies have investigated the synthesis of thermotropic liquid crystal polymer material that is composed of silver nanoparticles and CdSe [18]. In the last few years, researchers have been devoted to the preparation of high-quality $\mathrm{CdS}$ nanoparticles and the investigation of their various properties.

\section{Experimental method}

Isolation and identification

The bacteria were isolated from marine water and identified as Enterococcus sp. using biochemical tests and $16 \mathrm{~S}$ rRNA sequencing.

Extracellular synthesis of $\mathrm{CdS}$ nanoparticles

Enterococcus sp. culture was grown and maintained in nutrient agar medium. $100 \mathrm{ml}$ of nutrient broth was prepared, sterilized and inoculated with the culture of Enterococcus sp. and incubated at $37{ }^{\circ} \mathrm{C}$ for $24 \mathrm{~h}$. After incubation, the culture was centrifuged at 7,000 rpm for $10 \mathrm{~min}$ for extracellular synthesis of nanoparticles. After centrifugation, the supernatant was collected and $1 \mathrm{mM}$ of $\mathrm{CdSO}_{4}$ was added. After the addition of $\mathrm{CdSO}_{4}$, the culture was mixed well and incubated at $37^{\circ} \mathrm{C}$ for $24 \mathrm{~h}$. Any observed color change indicated nanoparticles synthesis and it was monitored using $\mathrm{UV}-\mathrm{V}$ is spectrophotometer.

\section{Characterization of $\mathrm{CdS}$ nanoparticles}

The reduction process of the solution was monitored on a Perkin Elmer double-beam UV spectrophotometer. The reaction of the aliquot solution was analyzed at different reaction times in the wavelength range between 300 and $700 \mathrm{~nm}$. The crystalline nature of the cadmium sulfide nanoparticles was characterized by X-ray diffraction. The reaction mixture was purified by repeated centrifugation at speed of $10,000 \mathrm{rpm}$ for $10 \mathrm{~min}$ and the pellets were dried at room temperature. The dried powders of cadmium sulfide nanoparticles were characterized by XRD (Philips PW 1830). The morphology and size of the cadmium sulfide nanoparticles was found by scanning electron microscope (SEM) (Philip model CM 200). Elemental analysis of $\mathrm{CdS}$ was carried out by EDAX. FTIR was obtained on a SHIMADZU instrument with the sample as KBR pellet.

Antibacterial activity of $\mathrm{CdS}$ nanoparticles

Antimicrobial activities of synthesized $\mathrm{CdS}$ nanoparticles were assayed by well diffusion method against the bacterial cultures of Serratia nematodiphila, E.coli, K.planticola and Vibrio which were purchased from MTCC, India. Approximately, $20 \mathrm{ml}$ of molten and cooled Muller Hinton agar was poured into the Petri dishes. The overnight growth test organisms were transferred over the agar medium and a $5 \mathrm{~mm}$-diameter well was made by gel puncture. After that, different concentrations of CdS nanoparticles, such as 50, 100 and $200 \mu \mathrm{l}$, were added to the well at $35^{\circ} \mathrm{C}$ for $24 \mathrm{~h}$ incubation. After incubation the zone of inhibition around the well was measured. All the experiments were followed three times for statistical analysis.

Antifungal activity of CdS nanoparticles

Antifungal activity of $\mathrm{CdS}$ nanoparticles was assessed against pathogenic Aspergillus niger and Aspergillus flavus by the well diffusion method. The fungal spores were inoculated into the Petri plates containing sterile Sabouraud dextrose agar and wells were made. Different concentration of CdS nanoparticles, 50, 100 and $200 \mu \mathrm{l}$, were poured into the well. All these plates were incubated for $48 \mathrm{~h}$ at room temperature. After incubation the inhibition zone was noted around the well.

\section{Results and discussion}

\section{Visual observation}

The present study shows the synthesis of cadmium sulfide nanoparticles by using Enterococcus sp. Herein, the cadmium sulfate was reduced to cadmium sulfide nanoparticles. Figure 1 shows the images of (a) bacterial culture without cadmium sulfate and with nutrient addition of cadmium sulfate (b) after $24 \mathrm{~h}$ incubation of cadmium sulfide with nutrient broth. The color of the solution changed from yellow to light white after $6 \mathrm{~h}$, confirming that the cadmium sulfide synthesis reaction had started. After $24 \mathrm{~h}$, the light white color turned to white, showing the reduction of cadmium sulfate into cadmium sulfide using Enterococcus sp. The intensity of the white color was increased on increasing the time of incubation. After $24 \mathrm{~h}$, no color change occurred, indicating that the CdS nanoparticles synthesis process was complete. Previously, [19] have reported the synthesis of $\mathrm{CdS}$ nanoparticles using Escherichia coli. 
Fig. 1 Time evolution of UVVis absorption spectra during the formation of CdS nanoparticles. Inset shows color change of synthesized CdS nanoparticles of a $24 \mathrm{~h}$ culture supernatant $\mathbf{b}$ after addition of $1 \mathrm{mM}$ cadmium sulfate into culture; the color change indicates the formation of $\mathrm{CdS}$ nanoparticles

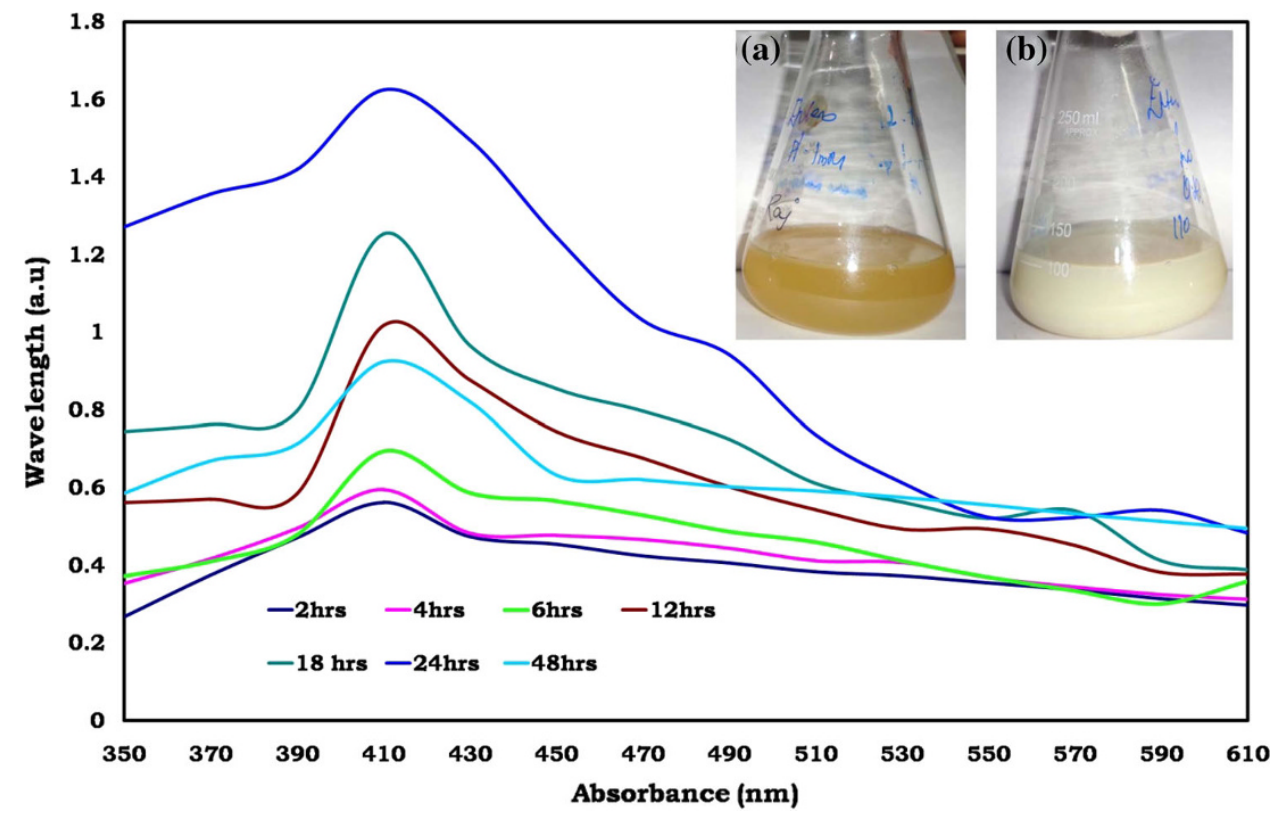

$\mathrm{UV}-\mathrm{V}$ is spectrophotometer

The synthesis of CdS nanoparticles using Enterococcus sp. at different time intervals was monitored by UV-Vis spectroscopy. Figure 1 shows the UV-Vis absorption spectra of the synthesized CdS nanoparticles using the culture supernatant of Enterococcus sp. The absorbance of CdS NPs was scanned from 300 to $620 \mathrm{~nm}$ for the aqueous reaction mixture. In Enterococcus sp.-derived CdS NPs, the absorbance of CdS NPs started at $2 \mathrm{~h}$ and ended at $24 \mathrm{~h}$. After $24 \mathrm{~h}$, there was high absorbance, indicating that the reduction process of cadmium sulfate into cadmium sulfide NP was complete. The attribute surface plasmon absorption bands were noticed at $410 \mathrm{~nm}$ and increase of nanoparticles size can also affect the SPR band broadening [20]. Thus, CdS nanoparticles solution synthesized using Enterococcus sp. was very stable for 3 months, which was detected by a surface plasmon resonance. Similarly, [21] reported that the CdS NPs was absorbed at $410 \mathrm{~nm}$ and was synthesized using $K$. pneumoniae.

\section{SEM}

The morphology and distribution of the synthesized CdS nanoparticles were examined by SEM analysis. SEM images of $\mathrm{CdS}$ nanoparticles were viewed at different magnifications of $5,000 \times$ and $10,000 \times$ (Fig. 2). The synthesized CdS nanoparticles are mostly spherical in shape and the size ranges varied from 50 to $180 \mathrm{~nm}$ (scale bar $1 \mu \mathrm{m})$. The images confirmed the formation of few nanoparticles capped with the biomolecules present in the bio- mass supernatant. The SEM images show that the synthesized CdS NPs are predominantly spherical in shape with aggregates [22]. This suggests that the protein molecules perform as surface-coating molecules which keep away from the internal agglomeration of the particle, indicating the stabilization of nanoparticles.

\section{EDS}

Energy-dispersive X-ray analysis (EDX) reveals the strong signal in the $\mathrm{Cd}$ and $\mathrm{S}$ confirming the reduction of $\mathrm{CdSO}_{4}$ into $\mathrm{CdS}$ nanoparticles by the action of Enterococcus sp. (Fig. 3). Semiconductor CdS nanocrystals generally show a representative visual absorption peak approximately at $3 \mathrm{keV}$ due to surface plasmon resonance [23]. The synthesized CdS nanoparticles were stable in solution for more than a period of 2 months at room temperature. Our EDX report correlated with the report [24].

Fourier transform infrared spectroscopy (FTIR)

The FTIR measurement was carried out for CdS nanoparticle formed after $24 \mathrm{~h}$ incubation with Enterococcus sp. Figure 4 shows the broad peak at $3272 \mathrm{~cm}^{-1}$ and $1630 \mathrm{~cm}^{-1}$ corresponding to primary and secondary amines or amide linkages in the protein. The strong peaks seen at $984 \mathrm{~cm}^{-1}$ are identified as those of the alkene groups due to the $=\mathrm{C}-\mathrm{H}$ bending vibrations. The stronger band at $548 \mathrm{~cm}^{-1}$ corresponds to the $\mathrm{C}-\mathrm{Br}$ stretching vibrations due to the alkyl halides groups. Sanghi and Verma [25] have reported that proteins can bind to CdS 

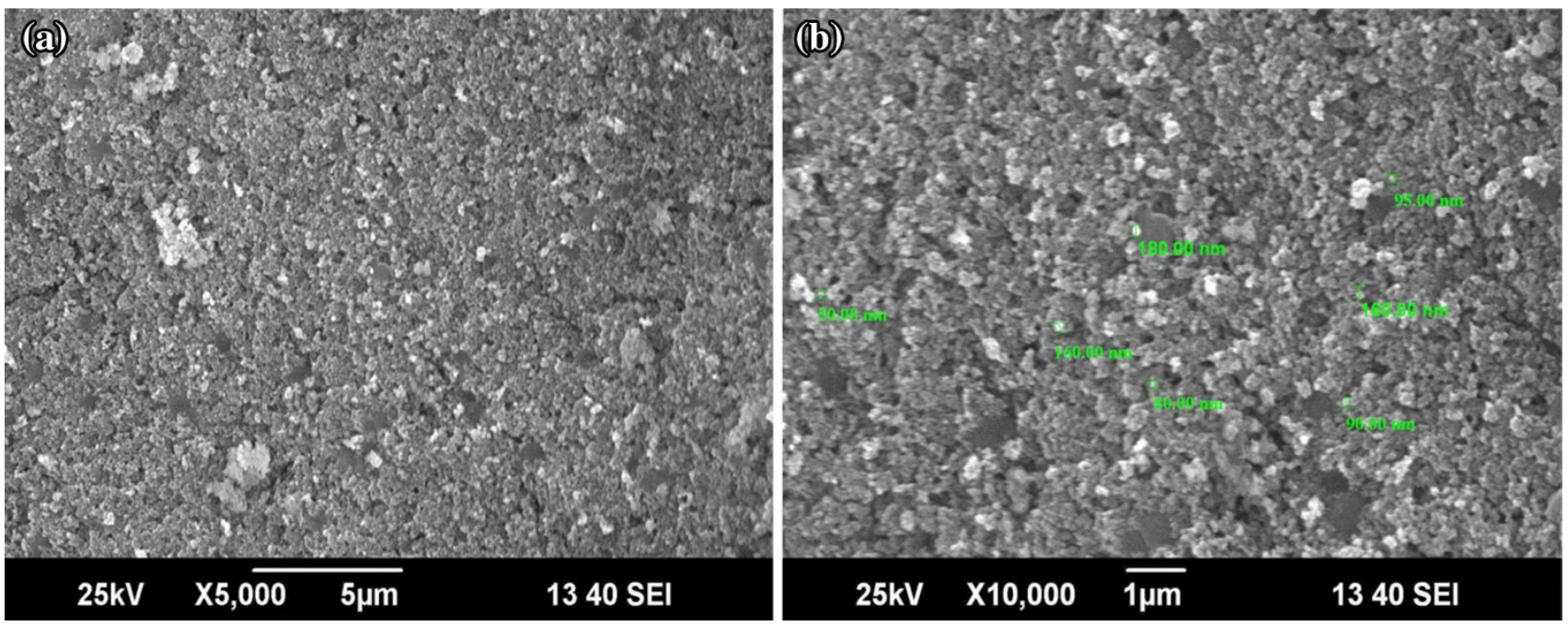

Fig. 2 SEM images illustrating the formation of CdS nanoparticles at different magnifications: $\mathbf{a} \times 5,000, \mathbf{b} \times 10,000$

Fig. 3 EDX pattern of CdS nanoparticles

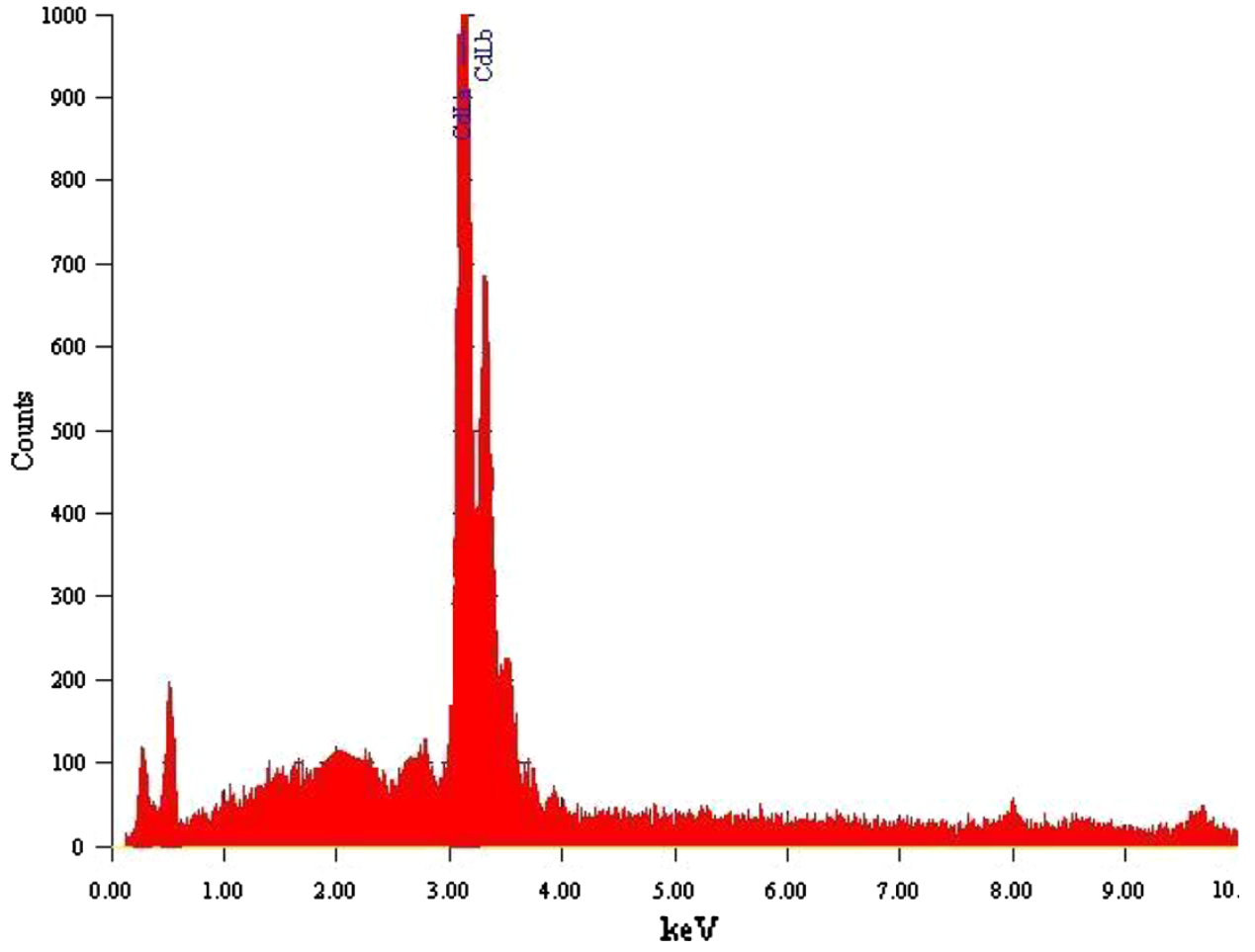

nanoparticles either through free amine groups or cysteine residues that have a vital role in the protein, and cystein residues play a vital role in $\mathrm{CdS}$ nanoparticles.

XRD analysis

The crystalline structure of synthesized CdS nanoparticles using Enterococcus sp. was characterized by XRD (Fig. 5). There is one intense peak in the whole spectrum of $2 \theta$ values ranging from 20 to 70 . A comparison of our XRD spectrum with the standard confirmed that the CdS particles formed in the present study as nanocrystals, as evident from the peaks at $2 \theta$ values of $26.3^{\circ}$ and integrated intensity values of (111) cubic $\mathrm{CdS}$ phase, respectively. These results are closer to the reported standard data JCPDS File No. 10-454 for synthesis of CdS nanoparticles. The full widths at half maximum (FWHM) values measured for (111) planes of reflection were used with the Debye-Scherrer equation to calculate the size of the nanoparticles: 


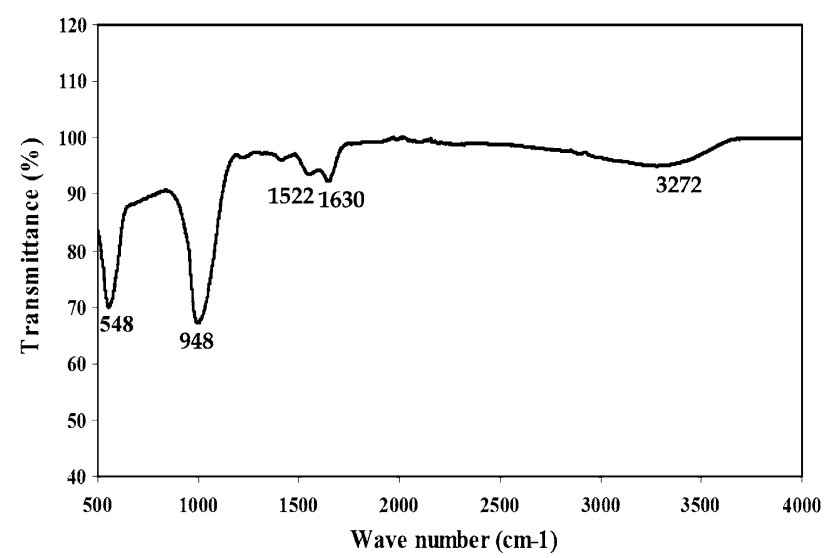

Fig. 4 FTIR absorption spectra of CdS nanoparticles

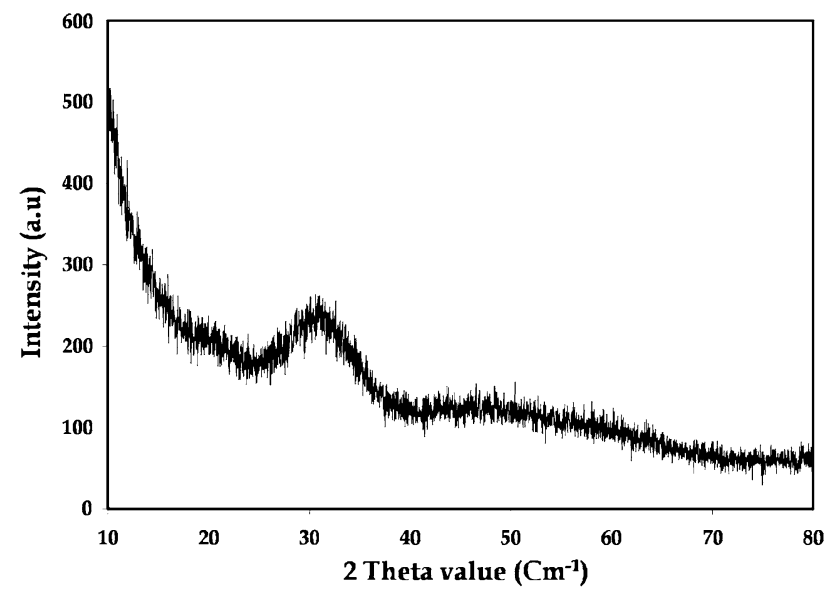

Fig. 5 XRD patterns of CdS nanoparticles

$D=K \lambda / \beta(\cos \theta)$.

The equation uses the suggestion peak width at Brag diffraction angle $\theta$, where $K$ is a Blank's constant, $\lambda$ is the source wavelength (1.54), and $\beta$ is the width of the XRD peak at half maximum height. The calculated average particle size of the cadmium sulfide nanocrystals was found to be $12 \mathrm{~nm}$.

\section{Bactericidal activity of CdS nanoparticles}

The bactericidal effects of spherical CdS nanoparticles have been investigated against clinical isolates of $S$. nematodiphila, E. coli, K. planticola and Vibrio sp. (Fig. 6; Table 1). Three different concentrations (50, 100 and $200 \mu \mathrm{l}$ ) were taken to inhibit pathogenic bacterial growth. The microbe-mediated CdS nanoparticles had the maximum zone of inhibition against disease-causing K. planticola, Planomicrobium sp. and Vibrio sp. The minimum zone of inhibition was observed against
S. nematodiphila and E. coli and the increase in nanoparticles concentration involved the high zone of inhibition. The structure of the cell wall difference between the Gram-positive and Gram-negative bacteria plays a role in the formation of the zone. In Gram-positive bacteria, the cell wall consists of a deep layer of membrane, consisting of linear polysaccharide chains, and the Gram-negative bacteria possess a slender layer of membrane [26]. The zone of inhibitory action of CdS nanoparticles of microorganism is partially identified. The positively charged CdS nanoparticles are join with the negatively charged microorganism by the electrostatic magnetism and the proteins present on the bacterial cell membrane [23]. Malarkodi et al. [23] suggest that the nanoparticles have large surface area available for interactions which enhances the antibacterial effect than the morphology of the nanoparticles. The antibacterial effects of stabilized cadmium oxide nanoparticles can be helpful in the treatment of infectious disease caused by E. coli. Shukla et al. [28] reported that microbes transmit a positive charge. This creates an "electromagnetic" attraction between the microorganisms and the treated cell outer membrane. The present study demonstrates that CdS nanoparticle has bactericidal activity against the entire test organism. Since this is easily available and is also used in hospitals as a biomedical agent, the energetic nano compound from this can be prepared and used effectively for preventing the growth of microbial pathogens.

\section{Antifungal activity of CdS nanoparticles}

CdS nanoparticles synthesized by bacteria are more toxic against $A$. niger and A. flavus, which was investigated by the well diffusion method. The various concentrations of nanoparticles, 50, 100 and $200 \mu \mathrm{l}$, were mixed with the medium and poured in Petri plates. After $48 \mathrm{~h}$, the plates showed the susceptible growth of fungus, which was decreased at the increased concentration of CdS nanoparticles. The maximum zone of inhibition was found in the $A$. flavus followed by $A$. niger. The zone of inhibition increased while increasing the concentration of $\mathrm{CdS}$ nanoparticles. The zone of inhibition is shown in Fig. 7. The mode of action of nanoparticles on fungi is through targeting the yeast cell membrane and disrupting membrane potential [27].

\section{Conclusion}

Enterobacter sp. was exploited for the biological synthesis of nanoparticles extracellularly. This involved secretion of enzyme sulfate reductase into culture supernatant which brought about the reduction of cadmium sulfate into 
Fig. 6 Antibacterial activity of $\mathrm{CdS}$ nanoparticles against different microorganisms a E. coli, b Vibrio sp. c $K$. planticola, d Planomicrobium sp. and e $S$. nematodiphila
Table 1 Antibacterial activity of CdS nanoparticles against different bacterial strains

Bold values indicate the highest zone of inhibition

\pm Standard deviation
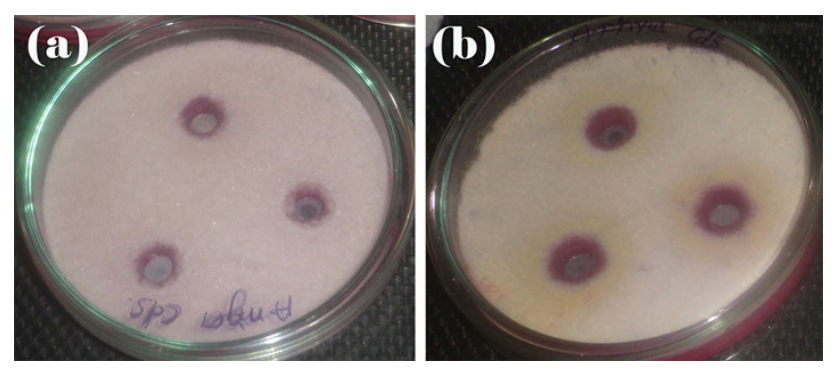

Fig. 7 Antifungal activity of CdS nanoparticles a A. niger, b A. flavus

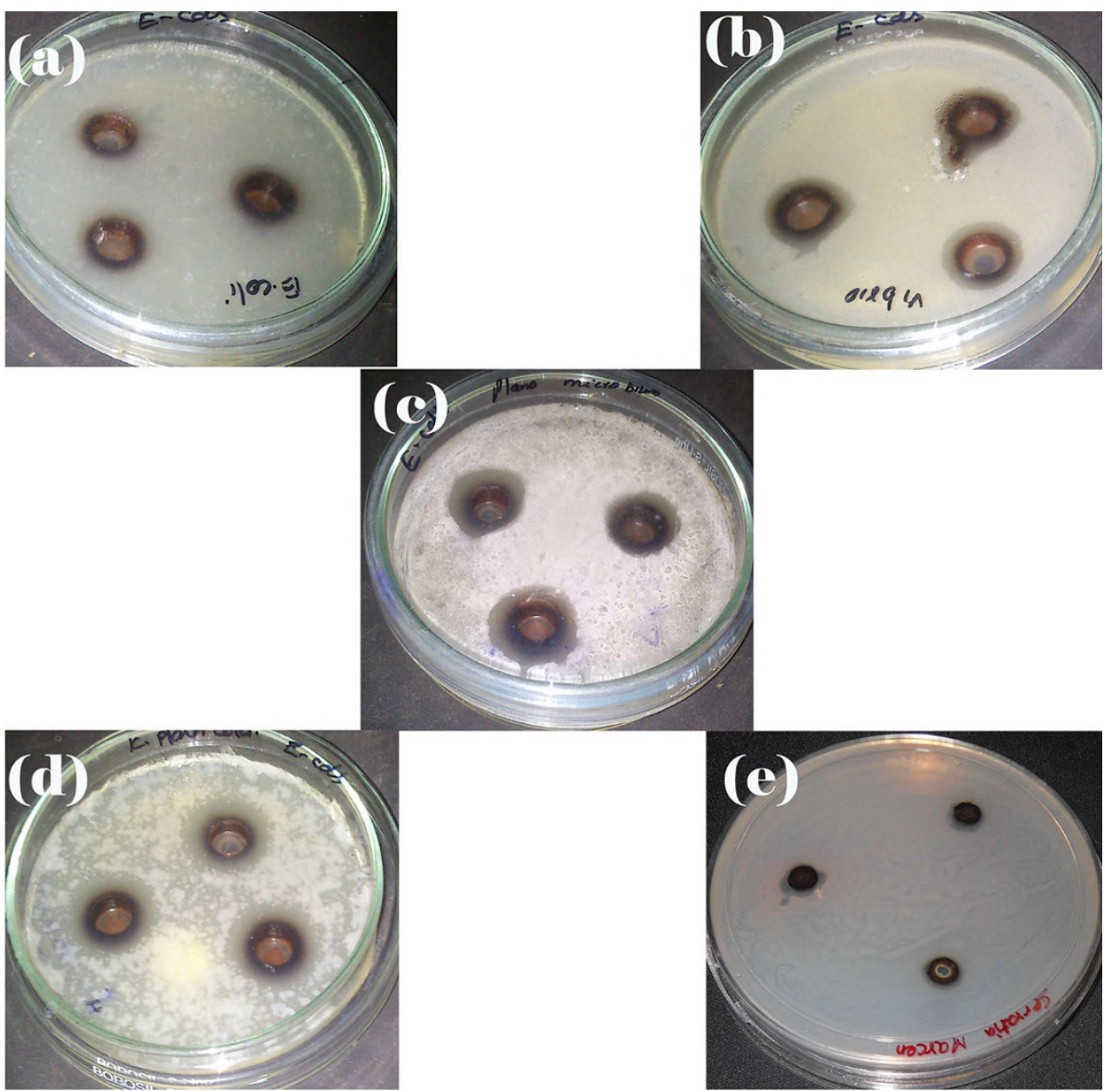

\begin{tabular}{lllll}
\hline $\begin{array}{l}\text { Concentration of CdS } \\
\text { nanoparticle }\end{array}$ & $50 \mu \mathrm{l}$ & $100 \mu \mathrm{l}$ & $200 \mu \mathrm{l}$ & $\begin{array}{l}\text { Standard } \\
\text { antibiotics }\end{array}$ \\
\hline
\end{tabular}

\begin{tabular}{lllll}
\hline Bacteria & \multicolumn{3}{l}{ Zone of inhibition $(\mathrm{mm})$} \\
E. coli & $8.17 \pm 0.088$ & $11.20 \pm 0.116$ & $16.16 \pm 0.334$ & $9.16 \pm 0.315$ \\
Vibrio sp. & $06.50 \pm 0.500$ & $10.10 \pm 0.208$ & $14.30 \pm 0.153$ & $6.20 \pm 0.112$ \\
Planomicrobium sp. & $7.33 \pm 0.334$ & $11.10 \pm 0.100$ & $18.27 \pm 0.146$ & $10.23 \pm 0.111$ \\
K. planticola & $\mathbf{1 0 . 3 0} \pm \mathbf{0 . 2 0 8}$ & $\mathbf{1 7 . 0 0} \pm \mathbf{0 . 0 0 0}$ & $\mathbf{2 3 . 2 7} \pm \mathbf{0 . 1 2 0}$ & $13.27 \pm 0.210$ \\
S. nematodiphila & $6.07 \pm 0.067$ & $10.20 \pm 0.153$ & $14.16 \pm 0.088$ & $7.16 \pm 0.080$ \\
\hline
\end{tabular}

cadmium sulfide nanoparticles. Enterobacter sp. was absorbed to have maximum production of nanoparticles at $410 \mathrm{~nm}$. The morphology and size of the CdS nanoparticles were observed to be $50-180 \mathrm{~nm}$. X-ray diffractometer showed the crystalline nature of nanoparticles. Fourier transform infrared spectroscopy showed that the functional groups of $\mathrm{CdS}$ nanoparticle could bind to proteins through free amine groups or carboxylate group in the protein. The results indicated that $\mathrm{CdS}$ nanoparticles have good antimicrobial activity against different microorganisms. It is confirmed that $\mathrm{CdS}$ nanoparticles have high antifungal 
efficacy and hence have a great potential in the preparation of biomedical applications.

Open Access This article is distributed under the terms of the Creative Commons Attribution License which permits any use, distribution, and reproduction in any medium, provided the original author(s) and the source are credited.

\section{References}

1. Albrecht, A: Evaluating dark energy probes using multi-dimensional dark energy parameters. DETF. 0609591, (2006)

2. Rajeshkumar, S., Malarkodi, C., Paulkumar, K., Vanaja, M., Gnanajobitha, G., Annadurai, G.: Intracellular and extracellular biosynthesis of silver nanoparticles by using marine bacteria vibrio alginolyticus. Nanosci. Nanotechnol. Int. J. 1, 21-25 (2013)

3. Malarkodi, C., Rajeshkumar, S., Paulkumar, K., Gnanajobitha, G., Vanaja, M., Annadurai, G.: Eco-friendly synthesis and characterization of gold nanoparticles using Klebsiella pneumonia. J. Nanostruct. Chem. 3, 30 (2013)

4. Malarkodi, C., Annadurai, G.: A novel biological approach on extra synthesis and characterization of semiconductor Zinc Sulfide nanoparticles. Appl. Nanosci. 3, 389-395 (2012)

5. Malarkodi, C, Chitra, K, Rajeshkumar, S, Paulkumar, K, Gnanajobitha G, Vanaja, M, Annadurai, G: Novel eco-friendly synthesis of titanium oxide nanoparticles by using Planomicrobium $\mathrm{sp}$, and evaluation of its antimicrobial activity. Der Pharmacia Sinica 4(3), 59-66 (2013)

6. Rajeshkumar, S., Kannan, C., Annadurai, G.: Synthesis and characterization of antimicrobial silver nanoparticles using marine brown seaweed Padina tetrastromatica. Drug Invention Today 4(10), 511-513 (2012)

7. Gnanajobitha, G., Rajeshkumar, S., Kannan, C., Annadurai, G.: Preparation and characterization of fruit-mediated silver nanoparticles using pomegranate extract and assessment of its antimicrobial activity. J. Environ. Nanotechnol. 2(1), 04-10 (2013)

8. Falkiewicz-Dulik, M., Macura, A.B.: Nanosilver as substance biostabilising footwear materials in the foot mycosis prophylaxis. Mikol. Lekarska 15, 145-150 (2008)

9. Verma, V.C., Kharwar, R.N., Gange, A.C.: Biosynthesis of noble metal nanoparticles and their application. Nutr. Nat. Resour. 4, 1 (2009)

10. Erra, S, Shivakumar, C, Zhao, H, Barri, B, Morel, DL, Frekides, CS: An effective method of $\mathrm{Cu}$ incorporation in CdTe solar cells for improved stability. Thin Solid Films 515(15), 5833-5836 (2007)

11. Lakowicz, J.R., Gryczynski, I., Piszczek, J., Murphy, C.J.: Emission spectral properties of cadmium sulfide nanoparticles with multiphoton excitation. J. Phys. Chem. (B) 106, 5365 (2002)

12. Ushakov, N.M., Yurkov, Y.G., Zapsis, K.V., Baranov, D.A., Kataeva, N.A., Kosobudskiř, I.D., Gubin, I.B.: Optical properties of cadmium sulfide nanoparticles on the surface of polytetrafluoroethylene nanogranules. Opt. Spectrosc. 100, 414 (2006)

13. Venkatram, N., Rao, D.N., Akundi, M.A.: Nonlinear absorption, scattering and optical limiting studies of CdS nanoparticles. Opt. Express 13, 867 (2005)

14. Bansal, P., Jaggi, N., Rohilla, S.K.: Green synthesis of CdS nanoparticles and effect of capping agent concentration on crystallite size. Res. J. Chem. Sci. 2(8), 69-71 (2012)

15. Chatterjee, M., Patra, A.: Cadmium sulfide aggregates through reverse micelles. J. Am. Ceram. Soc. 84, 1439 (2001)

16. Ghows, N., Entezari, M.H.: A novel method for the synthesis of CdS nanoparticles without surfactant. Ultrason. Sonochem. 18, 269 (2010)

17. Li Huang, Y.F., Zhang, Q., Gu, Z.: Solvothermal synthesis of nanocrystalline cadmium sulfide. J. Mater. Sci. 35, 5933 (2010)

18. Villars, P., Calvert, L.D.: Pearson's Handbook of Crystallographic Data for Intermetallic Phases, vol 2, (1985)

19. Rozamond, Y., Sweeney, C., Mao, X., Gao Justin, L.B., Angela, M.B., Georgiou, G., Brent, L.I.: Bacterial biosynthesis of cadmium sulfide, nanocrystals. Chem. Biol. 11, 1553-1559 (2004)

20. Dunne, M., Corrigan, O.I., Ramtoola, Z.: Influence of particle size and dissolution conditions on the degradation properties of polylactide-co-glycolide particles. Biomaterials 21, 1659-1668 (2000)

21. Mousavi, R.A., Akhavan Sepahy, A., Fazeli, M.R.: Biosynthesis, Purification and characterization of cadmium sulfide nanoparticles using Enterobacteriaceae and their application. In: Proceedings Of The International Conference Nanomaterials, vol. 1, applications and properties, no 1, pp. 2304-1862 (2012)

22. Andean, J.K., Kazemi, H., Mohsenzadeh, S., Safavi, A.: Biosynthesis of gold nanoparticles using dried flowers extract of Achillea wilhelmsii plant. Digest J. Nanomater. Biostruct. 6(3), 1011-1017 (2011)

23. Malarkodi C, Rajeshkumar S, Paulkumar K, GnanaJobitha G, Vanaja M, Annadurai G Biosynthesis of semiconductor nanoparticles by using sulfur reducing bacteria Serratia nematodiphila. Adv. Nanores. 1(2), 83-91 (2013)

24. Pandian, S.R.K., Deepak, V., Kalishwaralal, K., Gurunathan, S.: Biologically synthesized fluorescent CdS NPs encapsulated by PHB. Enzyme Microb. Technol. 48, 319-325 (2011)

25. Sanghi, R., Verma, P.: A facile green extracellular biosynthesis of $\mathrm{CdS}$ nanoparticles by immobilized fungus. Chem. Eng. J. 155, 886-891 (2009)

26. Vanaja, M., Annadurai, G.: Coleus aromaticus leaf extract mediated synthesis of silver nanoparticles and its bactericidal activity. Appl. Nanosci. 3, 217-223 (2012)

27. Kim, S., Sathishkumar, M., Sneha, K., Won, S.W., Cho, C.W., Yun, Y.S.: Cinnamon zeylanicum bark extract and powder mediated green synthesis of nano-crystalline silver particles and its bactericidal activity. Colloids Surf. B Biointerfaces 73, 332-338 (2009)

28. Shukla, M., Kumari, S., Shukla, S., Shukla, R.K.: Potent antibacterial activity of nano $\mathrm{CdO}$ synthesized via microemulsion scheme. J. Mater. Environ. Sci. 3(4), 678-685 (2012) 